\title{
COMISSIONAMENTO DE SISTEMAS PREDIAIS: APLICAÇÃO EM UM BANHEIRO SANITÁRIO
}

\author{
Commissioning of predial systems: Application in a sanitary bathroom \\ Andreson de Sousa FERREIRA ${ }^{1}$, Armando Traini FERREIRA ${ }^{2}$ \\ Recebido em 11 de agosto de 2019; aceito em 22 de abril de 2020; disponível on-line em 04 de março de 2020.
}

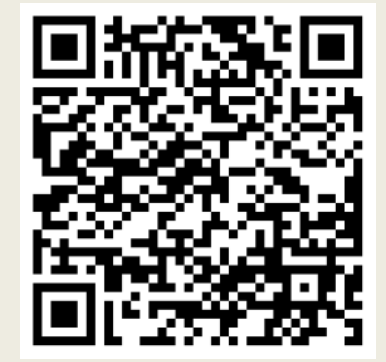

PALAVRAS CHAVE:

Sistemas prediais;

Comissionamento;

Banheiro sanitário;

Modelo conceitual;

Aplicação do processo;

\section{KEYWORDS:}

Building systems;

Commissioning;

Sanitary bathroom;

Conceptual model;

Process application.

\footnotetext{
* Contato com os autores:

${ }^{1}$ e-mail: sousandreson@gmail.com (A. S. Ferreira)

Engenheiro civil, graduado pelo Instituto Federal de Educação, Ciência e Tecnologia de São Paulo (IFSP)

2e-mail: traini@ifsp.edu.br ( A. T. Ferreira )

Engenheiro civil, Professor Doutor, Instituto Federal de Educação, Ciência e Tecnologia de São Paulo (IFSP)
}

\begin{abstract}
Increasingly, the concepts of projects and execution of civil works, such as maintenance of the building systems, are undergoing technological modifications aiming at the best planning, execution and performance. The Technological advances accompanied by good professionals contribute to the final quality of the enterprise. All this to meet the owner's design requirements. However, in face of this scenario, there are flaws in the designing buildings. So it can be observed the importance of design requirements as a process to meet the owners in the phases of building's life cycle, besides training professionals in the areas of operation and maintenance. Therefore the aim of this study is evaluate the application the commissioning process of building systems, taking as a case study, a bathroom toilet. With this, it is intended to contribute to the use of commissioning in the building installations as well as in the maintenance of systems and final quality of residential developments.
\end{abstract}




\section{INTRODUÇÃO}

Com constante atualização de novas tecnologias e o surgimento de novos modelos de projetos e execução de obras, surgem os sistemas de gerenciamento e controle de projetos. Sempre com a intenção de evitar erros técnicos, desperdícios e prejuízos, a busca por melhoria no sistema produtivo é um desafio a ser vencido pelos profissionais envolvidos desde a concepção, desenvolvimento, execução e manutenção de um empreendimento.

A definição prévia, clara e cuidadosa do escopo dos serviços envolvidos na elaboração de projetos, é uma necessidade para o início de qualquer projeto em qualquer tipo de empreendimento. No entanto, nem sempre acontece desta forma. Muitos projetos (grandes ou pequenos) começam com acordos mal ajustados entre seus idealizadores e os responsáveis pela preparação dos projetos (ABRASIP, 2010).

Dentre os sistemas prediais, podemos destacar o sistema de instalações hidráulicas. O fornecimento de água potável e o esgoto sanitário são uma necessidade nas instalações prediais. Dado tanta importância a este sistema, surge a necessidade de bons projetos e a sua devida interpretação. É fundamental a participação do projetista juntamente com o proprietário, bem como as demais equipes envolvidas no processo de planejamento e execução de um empreendimento (BORGSTEIN, 2016).

Diante disto, surge uma alternativa para se evitar tais falhas: o comissionamento. O processo de comissionamento, (ISHIDA, 2015) facilita a aplicação desta complexidade.

O conceito de comissionamento visa o melhor desempenho e qualidade dos serviços comissionados. Sendo assim sua utilização pode apresentar um bom resultado no alcance de bons desempenhos e eficiências energéticas. Neste contexto, este trabalho tem o objetivo de avaliar processo de comissionamento e realizar uma aplicação do mesmo a um banheiro sanitário.

\subsection{OBJETIVO}

O objetivo deste trabalho é apresentar o processo de comissionamento, de planejamento e gerenciamento de projetos e avaliar a aplicação deste processo, tomando como base um estudo de caso. Como objetivo específico, neste trabalho, serão analisadas as fases de um modelo conceitual de comissionamento em um banheiro sanitário, a fim de descrever as etapas do processo de comissionamento, demonstrar a aplicação do processo de comissionamento além de apresentar as potencialidades e benefícios ao se aplicar o processo de comissionamento.

\section{SISTEMAS PREDIAIS HIDRÁULICOS E SANITÁRIOS}

Conforme Santos (2002), a importância dos sistemas prediais na construção civil não está relacionado apenas à higiene pessoal e saúde, mas também com as noções de conforto impostas por um dinâmico comportamento social. Segundo Franco e Barros (2008) as edificações devem estar providas de diversos serviços que atendam plenamente as funções para as quais foram projetadas, e consequentemente, às necessidades dos usuários. Esse conjunto de serviços, segundo os autores, recebe a denominação de instalações prediais.

Segundo Gonçalves (2003) os sistemas sanitários prediais podem ser divididos em: subsistema de suprimento (água fria e água quente), subsistema de equipamento (aparelho sanitário) e subsistema de esgoto sanitário. De acordo com Paliari (2008), na fase de projeto é importante considerar as diversas interações com os demais subsistemas, de tal forma que o produto final represente aos quesitos de qualidade funcional esperados pelo usuário.

\section{COMISSIONAMENTO}

O comissionamento de instalações prediais é um processo de controle e qualidade 
que visa aferir o desempenho operacional da edificação. Começando na etapa de planejamento, ele avança pelas fases posteriores, chegando até a pós-ocupação. Com base no procedimento, é possível adotar providências ou medidas para que as metas definidas no início do projeto sejam atingidas (OROFINO; LARA 2017).

O comissionamento é um processo que tem a finalidade de atender aos requisitos de projeto do proprietário, documentar as fases do ciclo de vida do edifício, capacitar os profissionais de operação e manutenção, com o objetivo de evitar falhas, diminuir desperdícios e retrabalhos, melhorar a qualidade, o desempenho e a sustentabilidade (ISHIDA, 2015).

O Processo de comissionamento visa também validar e documentar o desempenho do edifício e seus subsistemas como também, propor o treinamento necessário aos operadores, de maneira que continuem a operar os equipamentos do edifício de forma eficaz e mantendo elevado desempenho (RIBEIRO, 2008).

Segundo Domingues (2008), em decorrência da complexidade das edificações, crescente multiplicidade dos sistemas prediais e tecnologias aplicadas, tudo isto aliado às necessidades dos diversos usuários, o processo de comissionamento pode e deve ser aplicado em edifícios residenciais, comerciais, industriais entre outros.

No entanto, se o processo começar na fase de concepção, os benefícios serão ainda maiores, uma vez que o inicio tardio do comissionamento dificulta o processo de documentação do edifício, a identificação dos erros de concepção e o desenvolvimento e condução dos testes funcionais, podendo deste modo, comprometer o potencial do comissionamento (OROFINO; LARA 2017).

$$
\text { Os diferentes conceitos de }
$$

comissionamento acima mencionados partilham o mesmo objetivo: construir edifícios que vão de encontro às necessidades do proprietário da obra e ou dos usuários, além de, proporcionar ambientes seguros e confortáveis e que sejam mantidos e operados por pessoas bem treinadas.

Para um processo de comissionamento eficaz é necessária uma participação ativa de todas as partes envolvidas, ou seja, equipes de arquitetura e engenharia, empreiteiros, agente comissionador e dono do empreendimento. A Figura 1 representa a inserção do comissionamento durante o ciclo de construção de um edifício.

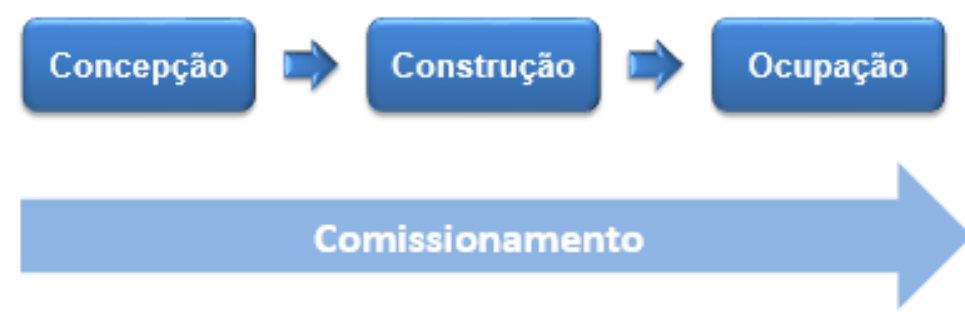

FIGURA 1: Inserção do Comissionamento durante o ciclo de construção de um edifício.

FONTE: Adaptado de Ribeiro (2008). 
Embora o conceito de comissionamento seja simples, o processo de comissionamento pode ser complexo porque envolve diversos profissionais em fases diferentes do ciclo de vida do edifício (GRONDZIK, 2009 apud ISHIDA, 2015).

Portanto, é um processo sistemático que ajuda a melhorar o desempenho e garante a qualidade do edifício, reduzindo os seus custos de operação e manutenção, melhora a sua eficiência energética e não energética e aumenta a segurança, conforto e saúde dos seus utilizadores (RIBEIRO, 2008).

\subsection{FASES DO COMISSIONAMENTO}

De acordo com Orofino et al. (2017) é possível dividir o processo de comissionamento em fases, admitindo-se: uma de projeto e outra de obra. A etapa inicial consiste na reunião de informações que definem os requisitos de projeto do proprietário, as premissas de projeto e o orçamento. Por fim, é estabelecido o plano de comissionamento e incorporados seus requisitos nos documentos de construção (plantas, memoriais, entre outros). Durante a obra são analisados os escopos e cláusulas das instaladoras a serem contratadas, de modo a garantir a execução do comissionamento.

Segundo Ribeiro (2008) o processo de comissionamento pode ser dividido em quatro fases principais, conforme demonstrado na Figura 2 e que se identificam como: planejamento, projeto, construção e operação/ manutenção. Em cada uma destas fases desenvolvem-se diferentes atividades por parte da equipe de comissionamento.

O processo de comissionamento ocorre durante várias fases do ciclo de vida do edifício. Muitas empresas aplicam $o$ processo de comissionamento somente da fase final de execução e início da fase de operação. Esta atitude não traz todos os benefícios do cumprimento dos requisitos de projeto do proprietário do que a aplicação do processo de comissionamento pleno, desde o início da concepção do edifício até um ano após o uso e operação do edifício, traz com os planejamentos necessários para correto planejamento, projeto, execução e operação da edificação (ISHIDA, 2015).

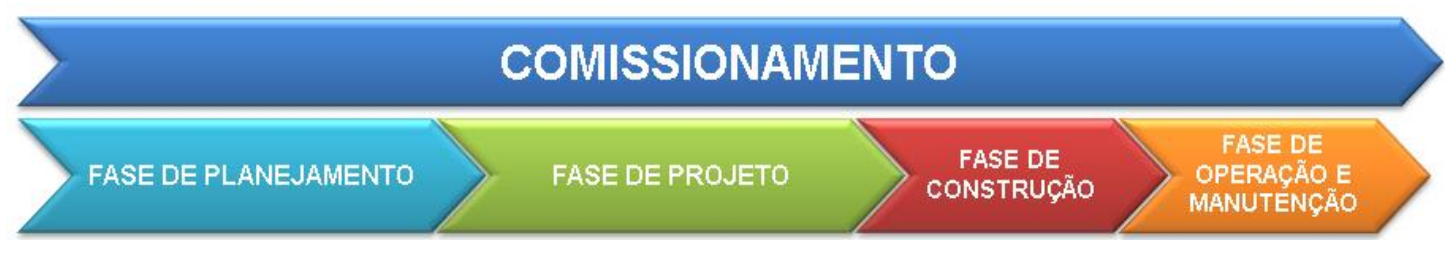

FIGURA 2: Fases do processo de comissionamento. FONTE: Adaptado Ishida (2015) 


\subsection{DOCUMENTOS GERADOS DURANTE AS FASES DO COMISSIONAMENTO}

Segundo Borgstein (2016) uma documentação completa e organizada facilita a elaboração dos projetos, execução da obra e futuras manutenções. A documentação é desenvolvida principalmente ao longo das fases do processo de comissionamento do edifício. A documentação é organizada pela equipe ou agente de comissionamento de modo a reunir todas as informações relevantes sobre o edifício e assim facilitar futuras intervenções

Para Ribeiro (2008) a documentação é desenvolvida principalmente ao longo da fase de planejamento, preparação e implementação, existindo quatro tipos principais de documentação: documentação de concepção, de processo, de verificação e de manutenção.

À medida que as atividades do processo de comissionamento são desenvolvidas, os documentos de comissionamento são gerados. Dentre os documentos gerados, pode-se destacar: Funções e responsabilidade, Requisitos de projeto do proprietário, Plano de comissionamento, Base de projeto, Relatório de revisão de projeto, Manual dos sistemas, Planos de treinamento e registros, Relatório final da garantia de comissionamento e Relatório de comissionamento (ISHIDA, 2015).

\subsection{MODELO CONCEITUAL DO PROCESSO DE COMISSIONAMENTO}

De acordo com Ishida (2015) a estrutura do modelo conceitual do processo de comissionamento de sistemas prediais em edifícios, segue o padrão dos manuais de escopo como, por exemplo, no manual de escopo de serviços de instalações hidráulicas da AGESC (2012) que é referenciado na norma brasileira de desempenho de sistemas hidrossanitários NBR 15575-6 (ABNT, 2013).

De acordo com ABRASIP (2010) o manual de escopo parte de uma sequência de atividades, organizada em fases bem definidas, que permitem determinar com clareza cronogramas, medições e outras etapas notáveis. As fases desenvolvidas, segundo SECOVI (2012), e referenciadas na norma brasileira de desempenho de sistemas hidrossanitários NBR 15575-6 (ABNT, 2013), são: Fase A (concepção do produto), fase B (definição do produto), fase $C$ (identificação e solução de interfaces), fase $D$ (projeto de detalhamento), fase $E$ (pós-entrega de projetos) e fase $F$ (pós-entrega da obra).

Neste modelo, segundo Ishida (2015), as fases do ciclo de vida são nomeadas conforme apresentado em AGESC (2012). Em cada fase do processo apresenta-se seu objetivo e é dividida em etapas.

Durante as fases do edifício, desde do projeto à construção, o processo de comissionamento deve proporcionar alguns atributos:

Fase A: identificar a equipe de comissionamento, desenvolver os requisitos de projeto do proprietário e estabelecer o escopo e orçamento do gerenciamento do comissionamento.

$\mathrm{Na}$ Fase B: desenvolver o plano de comissionamento, desenvolver a base de projeto, atualizar os requisitos de projeto do proprietário e incorporar o comissionamento nos escopos de serviços.

Na fase C: analisar a conformidade dos projetos e documentos e estabelecer a estrutura dos manuais dos sistemas.

Na fase D: validar os projetos conforme os requisitos, desenvolver planos de execução e testes, desenvolver requisitos de plano de treinamento e atualizar o plano de comissionamento.

Fase E: validar as versões de projetos e documentos, supervisionar as verificações de execução e testes, treinar os profissionais de operação e manutenção e atualizar os documentos.

E por fim Fase F: supervisionar os testes 
periódicos, inspecionar o desempenho final do comissionamento, avaliar a satisfação do proprietário e gerenciar reuniões de lições aprendidas.

\section{ESTUDO DE CASO}

Através do estudo de caso, é apresentada uma análise da aplicação do processo de comissionamento em um banheiro sanitário. $\mathrm{O}$ banheiro utilizado como estudo de caso, representado pela Figura 3, tem uma área construída de $3,85 \mathrm{~m}^{2}$, uma bacia sanitária modelo caixa acoplada, chuveiro tipo ducha com misturador de água fria e água quente, além de duas cubas de lavatório, ambas com pontos de água fria e água quente.

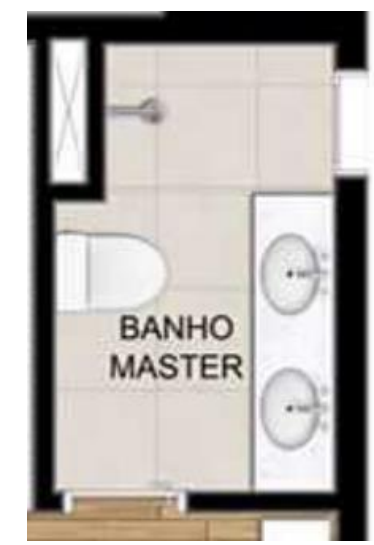

FIGURA 3: Banheiro de uma apartamento tipo. FONTE: Adaptado site construtora (2018).

Segundo Ishida (2015), o modelo conceitual para comissionamento de sistemas prediais, deve ser dividido em fases, conforme representando pela Figura 4. Modelo este, que segue o padrão dos manuais de escopo da AGESC (2012). Mediante o apresentado na revisão bibliográfica, percebe-se que o processo de comissionamento é um processo longo e que deve acompanhar todo o ciclo de um empreendimento, desde sua concepção até seu uso final.

Neste trabalho, não foi possível analisar o processo como um todo, uma vez que, para isto, seria necessário maior tempo de acompanhamento. Sendo assim, o processo de comissionamento foi analisado restringindo-se apenas as respectivas fases A, B, C, D, demonstradas na Figura 4.

\section{RESULTADOS E DISCUSSÕES}

Na fase A (concepção do produto), foram definidos: o escopo, representantes da equipe técnica e competências dos representantes. Feito isto, foram geradas planilhas a fim de documentar as Funções e Responsabilidades, além dos Requisitos de projeto do proprietário. Os representantes da equipe técnica foram convidados a participar deste processo, afim de contribuir por meio de suas experiências profissionais, para a análise do comissionamento. A participação, em reunião, da equipe técnica foi de grande importância para a elaboração dos Requisitos de Projeto do Proprietário, uma vez que, as experiências profissionais puderam contribuir para definição dos principais objetivos na construção do empreendimento.

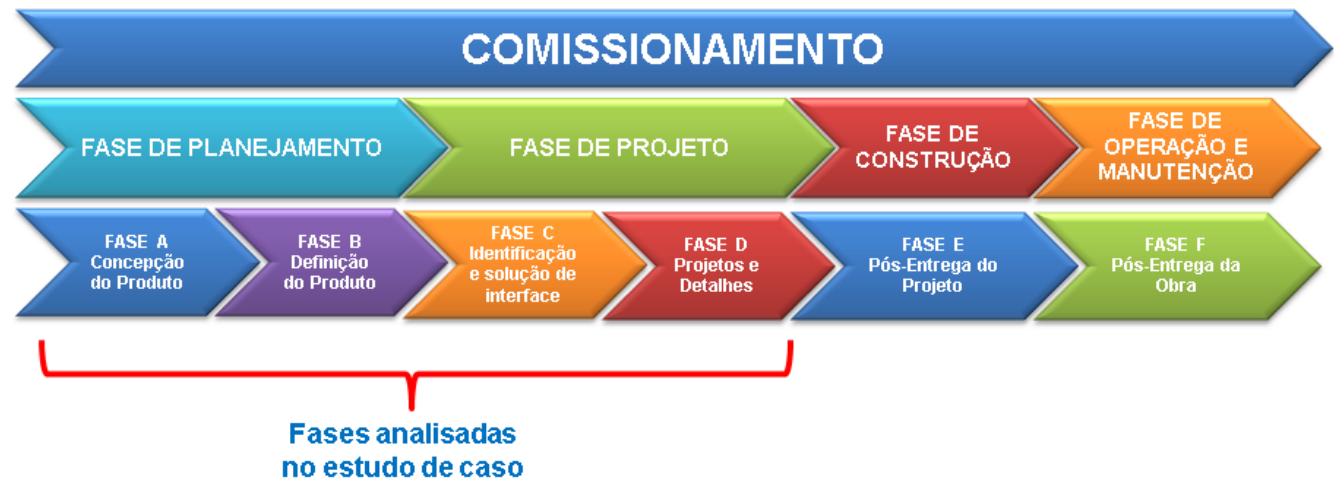

FIGURA 4: Fases analisadas no estudo de caso. FONTE: Adaptado de Ishida (2015). 
$\mathrm{Na}$ fase B (definição do produto) o agente de Comissionamento deu início ao desenvolvimento do plano de Comissionamento e a equipe de projetos desenvolveu os estudos preliminares a fim de viabilizar os Requisitos de Projeto do Proprietário. A fim de resguardar a qualidade dos projetos, o plano de comissionamento foi de grande importância nesta fase, uma vez que, por meio dele toda a equipe técnica obteve diretrizes que foram seguidas. Cabe destacar que, nesta fase foram determinados os layouts dos ambientes, bem como, através de definições prévias, o posicionamento de shafts e altura de entreforro necessária para a passagem de tubulações.

Outro assunto definido foi o processo de comunicação, ou seja, a estruturação dos meios de comunicação entre todos os envolvidos, tecnicamente, no processo. Admitindo que a construção de um empreendimento, desde a sua concepção até seu uso, demanda muito tempo, o devido rastreamento dos meios de comunicação, entre as partes envolvidas, é fundamental, uma vez que, deve-se evitar que informações se percam pelo caminho. Desta maneira foi estabelecida, além do uso de correspondências eletrônicas, a utilização de um sistema de compartilhamento online, ou seja, um sistema de nuvens.

Nesta fase foram apresentados, por parte da arquitetura, os estudos básicos com os layouts do banheiro master. $E$ por parte do projetista, os encaminhamentos das tubulações de esgoto e prumadas de ventilação, além dos ramais de alimentação de água fria e quente conforme observado na Figura 5. Cabe aqui destacar que estes são os produtos gerados nesta fase.

Para o sistema de abastecimento de água fria e quente, o projetista representante, sugeriu, conforme observado na Figura 6, a utilização do polietileno reticulado (PEX). Esta escolha foi baseada nos Requisitos de Projeto do Proprietário, uma vez que a construtora, estava interessada na utilização em produto com comportamento estrutural flexível.

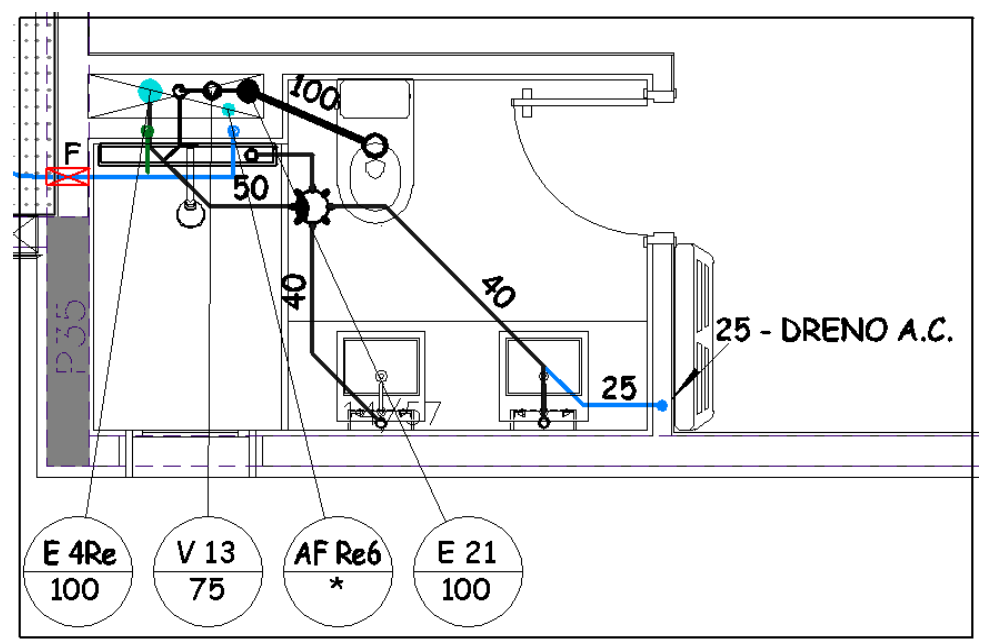

FIGURA 5: Estudo preliminar de ramais e sub-ramais de esgoto sanitário. FONTE: Adaptado projetista (2018). 


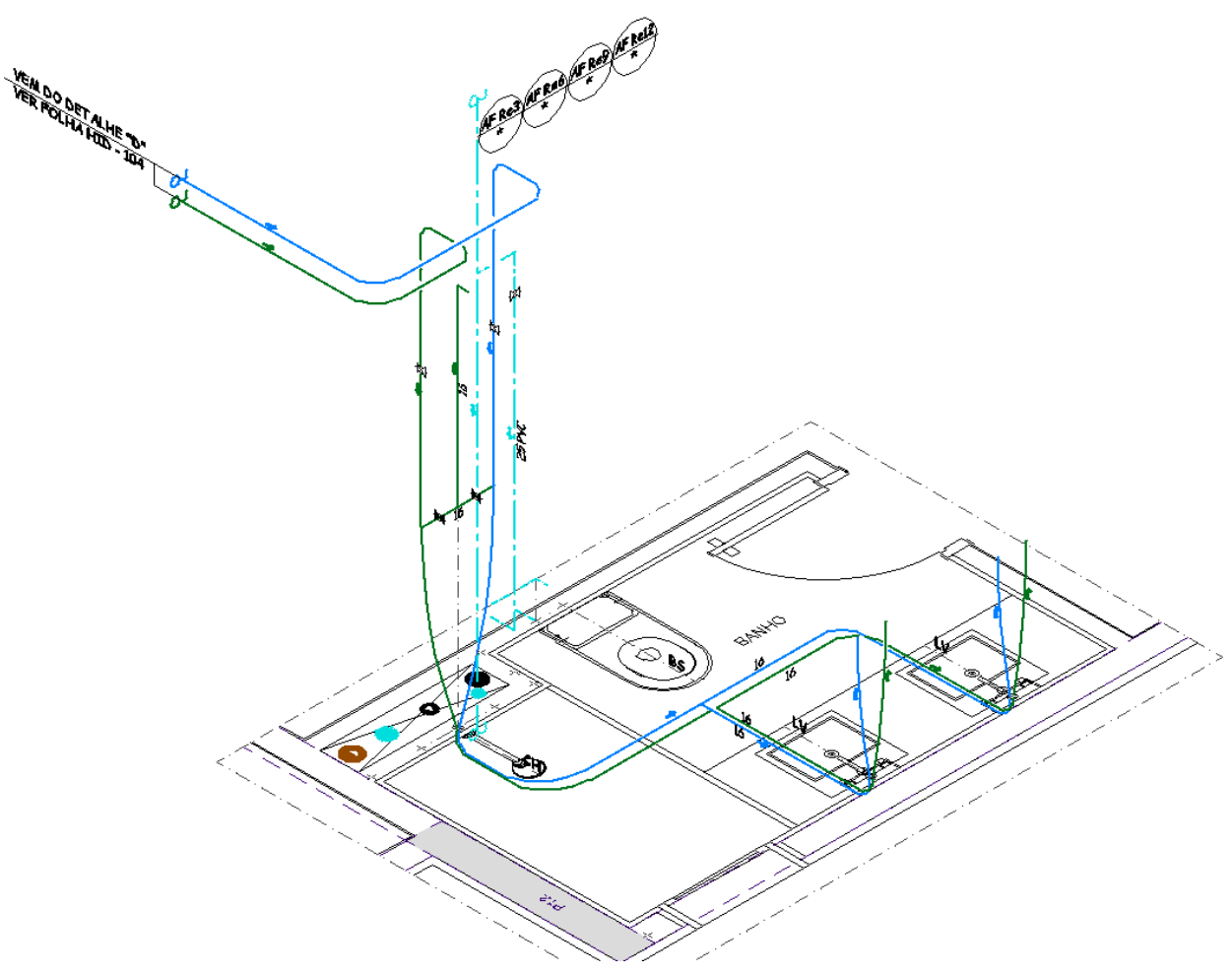

FIGURA 6: Estudo preliminar de ramais de água fria e quente.

FONTE: Adaptado projetista (2018).

A fase $C$ (identificação e solução de interfaces) teve como objetivo a consolidação do layout do banheiro master com as demais instalações. Assim, após a apresentação dos projetos, o coordenador pôde realizar as devidas revisões. Destas revisões, foi possível desenvolver o Informe de Projeto que é um produto gerado nesta fase.

Desta maneira, o agente de comissionamento deu início ao desenvolvimento do Manual de Sistema. Este manual é outro produto gerado nesta fase e foi elaborado com base nos demais documentos gerados até aqui. Nele foram descritas todas as informações necessárias para instalação, operação e manutenção dos sistemas.

É importante destacar que neste processo de revisão de projeto, o agente de Comissionamento foi fundamental para a reunião de todos os dados técnicos e para apurar os potenciais problemas decorrentes de escolhas erradas. Desta maneira, o mesmo pôde propor soluções adequadas ao empreendimento em questão.

A fase $D$ (projeto de detalhamento das especialidades) foi a última fase analisada neste estudo de caso e teve como objetivo a verificação das fases anteriores, ou seja, o agente de Comissionamento teve a função de analisar todos os itens até aqui mencionados. O coordenador de projetos e o projetista representante da Empresa 2 , assim como os demais, forneceram os projetos e documentos alterados e revisados para que assim, o gerente de Comissionamento pudesse desenvolver os informes de revisão de projeto, além do Plano de verificação da execução e testes.

É importante destacar que durante as fases de projeto, o processo de comissionamento também é dinâmico e acompanha tais fases, de modo a garantir que os projetos possam ser elaborados seguindo sempre diretrizes que mais se aproximam com o esperado por parte do cliente. Como pode ser observado na Figura 7, o projetista de instalações hidráulicas apresentou 
uma nova versão do projeto hidrossanitário, projeto este, com mais detalhes e de acordo com o novo requisito de projeto do proprietário.

Os projetos apresentados nesta fase foram desenvolvidos, como já mencionados, tendo como diretrizes, os documentos gerados durante as fases do processo de comissionamento. Por motivo de alteração para tubulação semi-rígida, foi descartada a utilização de tubos polietileno reticulado (PEX). E com base nesta informação o projetista apresentou um novo projeto de alimentação de água fria e água quente, conforme demostrada na Figura 8. Tal projeto executivo foi desenvolvido a partir do novo informe de revisão de projeto.

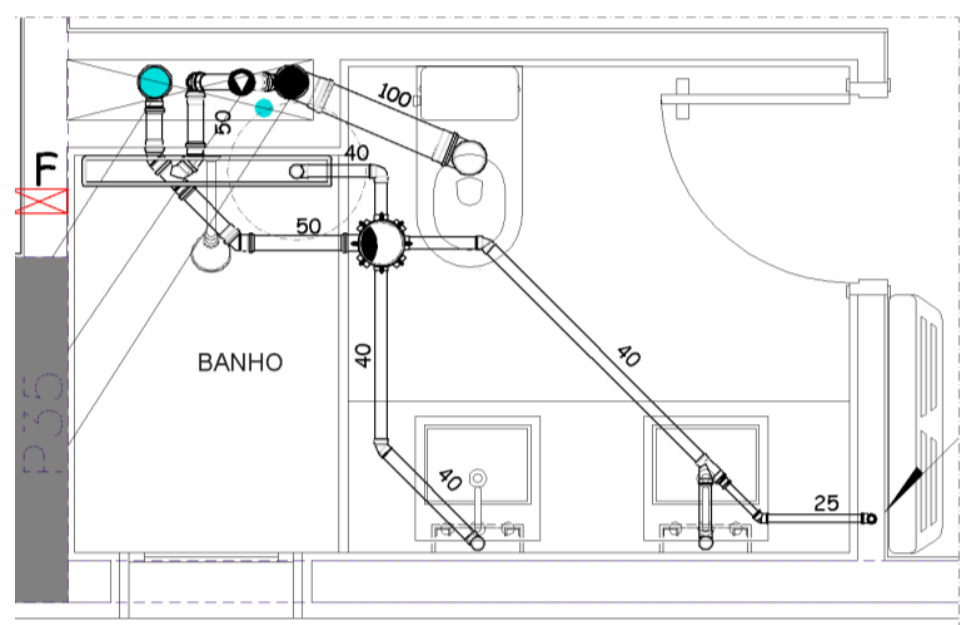

FIGURA 7: Projeto executivo ramais e sub-ramais de esgoto sanitário. FONTE: Adaptado projetista (2018).

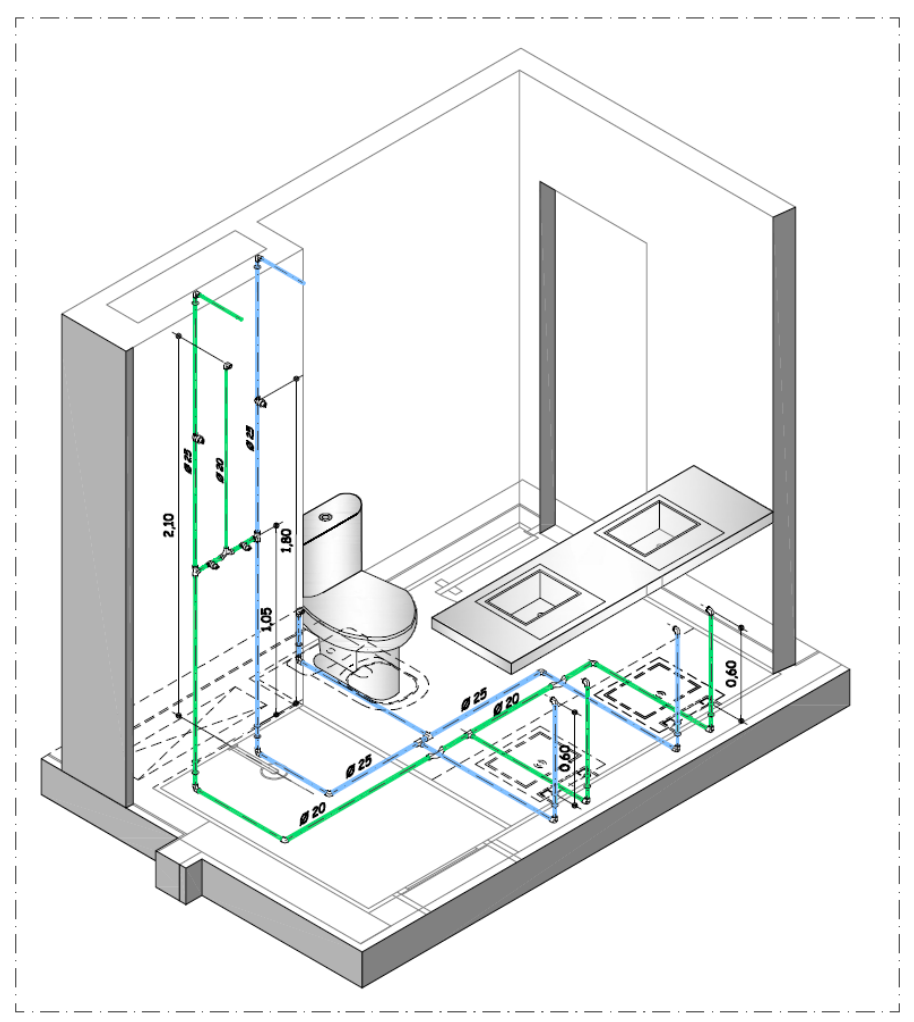

FIGURA 8: Projeto executivo dos ramais de água fria e quente. FONTE: Adaptado projetista (2018). 
Para a elaboração do Plano de verificação da execução e testes o agente de Comissionamento obteve auxilio do projetista para que os testes e verificações pudessem ser documentados corretamente. Cabe aqui mencionar que o Plano de verificação é um produto gerado nesta fase.

Este último documento gerado, neste estudo de caso, completa o processo de comissionamento aqui proposto. Pois, para que se possam analisar as demais fases do comissionamento, seria necessário maior tempo de acompanhamento, ou seja, verificar a execução da obra.

\section{CONSIDERAÇÕES FINAIS}

Por meio desta pesquisa, foi possível analisar o processo de comissionamento e sua aplicação; entender que o comissionamento pode ser utilizado com a finalidade de se obter melhores resultados construtivo, desde a concepção de um empreendimento, passando por todas as fases de projetos e obra, até o uso final. A fim de atender os requisitos de projeto de proprietário o processo de comissionamento foi fundamental para acompanhar o desempenho dos projetos, e posterior execução e manutenção de edifícios.

O comissionamento é um processo importante para assegurar que o projeto executivo seja construído e operado com sucesso. Esse processo é fundamental para o sucesso do funcionamento de um edifício.

Por meio das reuniões técnicas, percebeu-se que os projetistas entenderam claramente a necessidade do proprietário, ao passo que, o proprietário entendeu as razões dos projetistas e o agente de comissionamento pôde entender o desenvolvimento e a sequência das operações pretendidas, reduzindo problemas e elaborando a documentação para os executores e operadores.

O processo de comissionamento representa uma mudança em relação ao desenvolvimento de projetos e execução de obras, pois, de acordo com o analisado, percebeu-se que edifícios comissionados podem ser mais eficientes e mais econômicos ao longo do tempo, diminuindo assim, seus custos de manutenção e operação.

Desta forma nota-se que o processo de comissionamento, quando aplicado desde de a fase inicial do projeto, pode proporcionar melhor desempenho na elaboração dos projetos, evitando, por exemplo, desperdícios e retrabalhos e os produtos gerados em cada fase do comissionamento são fundamentais para que a equipe técnica possa ter diretrizes corretas a serem seguidas além de contribuir para o cumprimento dos prazos além de reduzir os pedidos de alteração de projetos identificando problemas de forma antecipada.

\section{REFERÊNCIAS BIBLIOGRÁFICAS}

ASSOCIAÇÃO BRASILEIRA DE NORMAS TÉCNICAS, NBR 5626: Instalações prediais de água fria - projetos. Rio de Janeiro, 1998.

NBR 8160: Instalações prediais de esgoto sanitário - Projeto e execução. Rio de Janeiro, 1999.

NBR 9648: Elaboração de projetos de edificações - Projeto e execução. Rio de Janeiro, 1995.

NBR 15575: Desempenho - Parte 6 - Sistemas hidrossanitários - Edifícios habitacionais. Rio de Janeiro, 2008.

ASSOCIAÇÃO BRASILEIRA DE ENGENHARIA DE SISTEMAS PREDIAIS (ABRASIP). Manual de escopo de contratação de projetos. 2016 Disponível em: < http://www.abrasip.org.br/cub/manuaisdeescopo->. Acesso em: 15 set. 2016.

ASSOCIAÇÃO BRASILEIRA DOS GESTORES E COORDENADORES DE PROJETO (AGESC). Manual de escopo de projetos e serviços de coordenação de projetos. 2. ed. [São Paulo]: nov. 2012. Disponível em: <http://www.manuaisdeescopo.com.br/Manual/Ver/14 49>. Acesso em: 12 jun. 2018.

BORGSTEIN, E. Os benefícios do comissionamento e retrocomissionamento. São Paulo. 2016. Disponível em: <http://www.mitsidi.com.br/comissionamento-eretrocomissionamento/?lang=pt-br>. Acesso em: 16 mai. 2018 
BOtelHO, M. H. C. \& RIBEIRO Jr., G. de A. (1998). Instalações hidráulicas prediais feitas para durar usando tubos de pvc. São Paulo: ProEditores, 230p. il.

CREDER, H. (2006). Instalações hidráulicas e sanitárias. Rio de Janeiro: LTC - Livros Técnicos e Científicos Editora, 6a Edição. 423p. il.

DOMINGUES, L. C. F. Estudo sobre comissionamento de edifícios comerciais monousuários e o gerenciamento de facilidades. 2008. 85 p. Monografia (MBA em Gerenciamento de Facilidades) - Escola Politécnica, Universidade de São Paulo, Programa de Educação Continuada em Engenharia, São Paulo, 2008. Disponível em:< http://www.poliintegra.poli.usp >. Acesso em: 14 abr. 2016.

FILHO, F. M. Comissionamento de infraestrutura. São Paulo. Palestra Fazion. 2014. Disponível em:< http://www.fazion.comi.br/documentos/comissioname nto-de-infraestrtutura.pdf>. Acesso em: 5 jun. 2016.

ISHIDA, CHRISTIANNE DOS SANTOS FIGUEIREDO. Modelo Conceitual para Comissionamento de Sistemas Prediais. São Paulo, dezembro, 2015. Dissertação (Mestrado em engenharia civil) - Escola Politécnica da Universidade de São Paulo. Disponível em:< http://www.teses.usp.br/teses/disponiveis/3/3146/tde -17062016-114157/pt-br.php Acesso em: 20 jun. 2016.

HOFFMANN, C. W. Comissionamento, qualificação e validação. e|a engenharia arquitetura. São Paulo. 2017. Disponível em:< http://www.engenhariaearquitetura.com.br/2018/01/c omissionamento-qualificacao-e-validacao>. Acesso em: 15 fev. 2018.

OROFINO, Z. M.; LARA. A. Comissionamento de instalações prediais garante bom desempenho operacional. São Paulo: 2017. Disponível em:< https://www.aecweb.com.br/cont/m/rev/comissionam ento-de-instalacoes-prediais-garante-bom-

desempenho-operacional_18257_10_0>Acesso em: 4 mar. 2018.

RIBEIRO, G. F. A. Comissionamento de edifícios novos. 2008. 65 p. Monografia (tese de mestrado) - Instituto superior técnico, Universidade técnica de Lisboa, Disponível em:< https://fenix.tecnico.ulisboa.pt/downloadFile/3951378 72651/disserta\%E7\%E3>. Acesso em: 20 abr. 2017. 